Marcia Cristina Teixeira Martins, Adventist University of Plata, Argentina

Reviewed by:

Giana Zarbato Longo,

Federal University of Santa

Catarina, Brazi

Emmanouella Magriplis, Agricultural University of Athens,

Greece

*Correspondence:

Andréia Q. Ribeiro

andreia.ribeiro@ufv.br

${ }^{\dagger}$ Present address:

Laís M. R. Loureiro,

Health Sciences Postgraduate Program, Universidade de Brasilia,

Brasilia, Brazil

Luciene F. F. Almeida,

Public Health Postgraduate Program,

Universidade Federal de Minas Gerais,

Belo Horizonte, Brazi

Milene C. Pessoa

Department of Nutrition, Universidade

Federal de Minas Gerais,

Belo Horizonte, Brazi

Specialty section:

This article was submitted to

Nutritional Epidemiology,

a section of the journal

Frontiers in Nutrition

Received: 13 December 2020 Accepted: 19 March 2021

Published: 07 May 2021

Citation:

Loureiro LMR, Almeida LFF,

Machado CJ, Pessoa MC,

Duarte MSL, Franceschini SCC and

Ribeiro AQ (2021) Food Consumption and Characteristics Associated in a

Brazilian Older Adult Population: A

Cluster Analysis.

Front. Nutr. 8:641263.

doi: 10.3389/fnut.2021.641263

\section{Food Consumption and}

\section{Characteristics Associated in a}

\section{Brazilian Older Adult Population: A Cluster Analysis}

\author{
Laís M. R. Loureiro ${ }^{1 \dagger}$, Luciene F. F. Almeida ${ }^{1 \dagger}$, Carla J. Machado ${ }^{2}$, Milene C. Pessoa ${ }^{1 \dagger}$, \\ Maria Sônia L. Duarte ${ }^{1}$, Sylvia C. C. Franceschini ${ }^{1}$ and Andréia Q. Ribeiro ${ }^{1 *}$ \\ ${ }^{1}$ Department of Nutrition and Health, Universidade Federal de Viçosa, Viçosa, Brazil, ${ }^{2}$ Department of Preventive and Social \\ Medicine, School of Medicine, Universidade Federal de Minas Gerais, Belo Horizonte, Brazil
}

Epidemiological studies support diet as a factor in the prevention and treatment of non-communicable chronic diseases, whose occurrence increases with age due to the poor choices or the adoption of a monotonous diet. The aim of this study was to construct the food consumption profiles of older adults of a Brazilian city to identify the main food groups and eating habits that contribute to these profiles and to estimate its association with socioeconomic characteristics, health and use of health services, lifestyle, and anthropometric indicators. This is a population-based cross-sectional study conducted with a representative sample of 621 community-dwelling older adults $(\geq 60$ years) in Viçosa, Minas Gerais, Brazil. The food consumption profile was the dependent variable obtained from a Food Frequency Questionnaire, utilizing the two-step cluster method. The multiple multinomial logistic regression model was used to estimate the independent associations, obtaining the odds ratios and 95\% confidence intervals. Three clusters were generated, namely, (1) "unhealthy" (2) "less unhealthy," and (3) "fairly healthy." The cluster "unhealthy" was characterized by a regular consumption of beans, fats, fatty/processed meats, and whole milk. The factors independently associated with this cluster were lower education level, lower individual income, history of at least one doctor's appointment in the year preceding this study, and being a former smoker. The cluster "less unhealthy" was characterized by a regular consumption of beans, green vegetables, vegetables and fruits, as well as fats, fatty/processed meats, and whole milk. The factors independently associated with the "less unhealthy" cluster were lower education level and history of at least six doctor's appointments in the prior year. The cluster "fairly healthy" was characterized by the same pattern of "less unhealthy," except for skim milk and low-fat dairy products. The evidence of the associations indicates the profile of older adults who require greater attention and care related to improved nutrition. The illiterate or semi-literate aged individuals, those with low income, and those who neglect to seek medical advice must be the focus of healthy eating actions and programs.

Keywords: food consumption, nutritional epidemiology, eating habits, aging, older adults, cluster analysis 


\section{INTRODUCTION}

Maintenance of the independence of older adults as well as their effective participation in society is directly linked to the preservation of their health, which is influenced by various factors, including lifestyle (1). In this context, the epidemiological and review studies offer evidence to support the importance of diet as a factor in the prevention and treatment of various non-communicable chronic diseases like diabetes, dyslipidemia, hypertension, and obesity (2-4), which pose challenges to the health professionals given that their occurrence increases dramatically with advancing age (5). Due to the poor choices or the adoption of a monotonous diet, the aged individuals may experience deficiencies of essential nutrients necessary to maintain health and appropriate disease control $(4,6)$.

Studies available in the literature also deepen the understanding of the determinants of eating habits in various populations. Within the scope of the older adult population, international studies have demonstrated that higher income, greater education level, and less cognitive impairment are associated with better nutrition (3, 7-9), while diet deficiencies and unhealthy eating habits are associated with male gender, obesity treatment (10), history of myocardial infarction, ischemic heart disease, and heart failure (11). In Brazil, nutritional epidemiology focused on aging is still a relatively new field of study, and only a few studies have investigated the determinants of eating habits of older adults. From these studies, a positive association has been identified between adequate eating habits and female gender, higher education (12-14), advancing age, a greater number of comorbidities (15), non-smoking $(13,14)$ overweight, and a history of consultation with a nutritionist $(13,14)$. On the other hand, low diet quality was associated with male gender, age $<80$ years, lower education, problems in affording food (16), smoking habit, underweight, mouth or teeth problems, and having $<4$ meals a day $(17,18)$.

Although there is an increase in the number of studies on food consumption among older adults in Brazil, little is known about this phenomenon in smaller cities. Social, economic, and cultural differences are significant among the Brazilian subpopulations, and the effectiveness of the promotion of healthy eating habits is influenced by these distinctions. In addition, grouping aged individuals according to their eating habits allows the identification of more vulnerable profiles that need more attention from public policies. This approach is still scarce in Brazil.

Thus, the aim of this study is to construct and describe the food consumption profiles of the older adult population of a medium-sized Brazilian city, by identifying the main food groups and eating habits that contribute to these profiles, and to estimate the association of the social and demographic characteristics, health and use of health services, lifestyle, and anthropometric indicators with these profiles.

\section{MATERIALS AND METHODS}

\section{Study Design and Participants}

This was a population-based, cross-sectional study-part of the project "Health conditions, nutrition, and use of medication by older adults in Viçosa (Minas Gerais): a population-based survey." Viçosa is a medium-sized Brazilian city located in the region of Zona da Mata in the state of Minas Gerais.

The study population consisted of older adults, aged 60 years or more, who are non-institutionalized residents in the municipality, including rural and urban areas. The target population was 7,980 individuals. The sample size was calculated with a confidence level of $95 \%$, with an estimated prevalence of $50 \%$ for different outcomes of interest in the larger project, a tolerated error of $4 \%$, and $20 \%$ to cover losses. Based on the calculation, the total number obtained was 670 individuals. There were losses by refusal $(n=24,3.6 \%)$ due to death, address not found, and emigration from the city $(n=25,3.7 \%)$. Losses did not differ by gender and age group. The participants were selected and interviewed according to the description of Nascimento et al. (19). The final sample consisted of 621 participants.

The interviews were pre-scheduled and conducted in the participants' houses by previously trained nutritionists paired with final-year undergraduate nutrition students. The present study was conducted according to the Declaration of Helsinki. The research project was approved by the Research Ethics Committee of the Federal University of Viçosa (ref. 27/2008). All the participants signed the informed consent form.

\section{Study Variables}

\section{Social, Demographic, and Economic Variables, Health Conditions, and Lifestyle}

The social and demographic variables of interest included sex (male, female), age range (60-69, 70-79, and 80 years or more), education level (never studied, $<8$ years of study, 8 years of study or more), income (quartiles), and cohabitation (lived alone, resided with someone else).

The variables of health conditions were self-perception of health (very good/good, regular, poor/very poor), hospital admissions (none, one, or more), and number of doctor's appointments (none, one to five, six or more) in the year preceding the interview as an indicator of healthcare or need for medical care. The functional ability was assessed using the questions regarding the ability to perform 14 basic and instrumental daily life activities, and the answer options included no difficulty, little difficulty, great difficulty, unable to do, and do not do (19). Besides the variable functional ability, the variables of instrumental daily life activities such as difficulty in eating and difficulty in preparing food were considered. The functional ability was defined as inadequate when the participant reported difficulty with the performance of seven or more activities or when they evaluated themselves as unable to perform three or more activities. Otherwise, the functional ability was defined as adequate (20). Polypharmacy, which was considered in this study, is defined as the use of five or more drugs (21). The 15-day recall period was defined in line with the literature to minimize memory bias $(21,22)$. Regarding the history of chronic disease, the following question was posed: "Even once in your life, has a doctor or any other health professional ever mentioned that you have or have had any of these diseases?" For the analysis, a history of diabetes, high blood pressure, dyslipidemia, and depression were used. The development of the instrument used to obtain information on health conditions was based on validated 
TABLE 1 | Classification of foods in groups of healthy and unhealthy eating indicators.

\begin{tabular}{|c|c|c|}
\hline Food Groups & & Foods \\
\hline \multirow[t]{6}{*}{$\begin{array}{l}\text { Healthy Eating } \\
\text { Indicators }\end{array}$} & $\begin{array}{l}\text { Beans }^{\mathrm{a}} \text { and Green } \\
\text { vegetables }^{\mathrm{a}}\end{array}$ & $\begin{array}{l}\text { Black, brown, and red } \\
\text { beans }\end{array}$ \\
\hline & Other vegetables ${ }^{a}$ & \\
\hline & Fruits $^{a}$ & \\
\hline & Skim milk and low-fat dairy & Skim milk \\
\hline & products $^{a}$ & $\begin{array}{l}\text { White cheese (Minas } \\
\text { cheese }^{d} \text { ) }\end{array}$ \\
\hline & & Ricotta \\
\hline \multirow{19}{*}{$\begin{array}{l}\text { Unhealthy eating } \\
\text { indicators }\end{array}$} & Whole milk ${ }^{\mathrm{b}}$ & \\
\hline & Soda $^{\mathrm{C}}$ & \\
\hline & Processed foods in general ${ }^{c}$ & Cracker \\
\hline & & Cornstarch cookie \\
\hline & & Pound cake \\
\hline & & Lasagna \\
\hline & & Fried "pastel"e \\
\hline & & Pizza \\
\hline & Sweets ${ }^{c}$ & Sweets in general (desserts) \\
\hline & & Frosted cake \\
\hline & & Chocolate \\
\hline & Fatty/processed meats ${ }^{b}$ & Fried chicken \\
\hline & & Sausage \\
\hline & & Wiener \\
\hline & & Pork rinds \\
\hline & & Ham/salami \\
\hline & Fats $^{b}$ & Margarine \\
\hline & & Butter \\
\hline & & Lard \\
\hline
\end{tabular}

Source: Adapted from Ministério da Saúde do Brasil Nigitel 2016) (28).

a Healthy eating indicators, if they were consumed five times/week or more. For the group of "other vegetables," yam, cassava, and potatoes were excluded.

${ }^{b}$ Unhealthy eating indicators, if they were consumed at least once a week.

${ }^{c}$ Unhealthy eating indicators, if they were consumed five times/week or more.

${ }^{d} A$ kind of cheese very popular in the state of Minas Gerais, Brazil.

e Traditional Brazilian food prepared with wheat flour dough and various fillings.

questionnaires as used by large national health surveys and prospective health studies with older adult populations (23-25).

Regarding their lifestyle, the seniors were questioned about their consumption of alcoholic beverages (yes; no, but used to drink formerly; never drank at all) and smoking (yes; no, but used to smoke formerly; never smoked at all). Besides that, they were questioned about a decrease in food intake due to loss of appetite, digestive problems, and chewing or swallowing difficulties within 3 months prior to the interview (26).

\section{Anthropometric Variables}

Concerning nutritional status, we calculated the body mass index $\left(\mathrm{kg} / \mathrm{m}^{2}\right)$, the waist-to-hip ratio, and the waist-to-height ratio. All these rates were used in the analysis as continuous variables besides waist circumference (27).

\section{Food Consumption Variables}

Regarding food consumption variables, the data collection instrument was a Food Frequency Questionnaire (FFQ) consisting of a long list of foods and consumption frequency options: once a day, two or more times a day,2-4 times a week, 5-6 times a week, once a week, twice a week, monthly, and never or rarely. The foods presented in the FFQ were grouped and classified as "healthy" and "unhealthy" eating indicators. Food groups classified as healthy eating indicators included beans, green vegetables, other vegetables, fruits, skim milk, and low-fat dairy products. Food groups classified as unhealthy eating indicators were whole milk, soda, processed foods in general, sweets, fatty / processed meats, and fats (saturated and trans-fat) (Table 1). According to the methodology of a national study in Brazil, entitled Protective and Risk Factors for Chronic Diseases by Telephone Survey (VIGITEL) of the year 2016, the consumption of each group was considered "regular" when some foods of the group were consumed at least five times a week and was considered "non-regular" when it was consumed up to four times a week. The exceptions were the consumption of whole milk, fats, and fatty/processed meats, which were considered unhealthy eating indicators with a regular consumption even when they were consumed once a week (28).

\section{Statistical Analysis}

The profile of food consumption was obtained from categorizing the individuals based on the frequency of consumption of the food groups listed in the FFQ. To obtain this variable, we used the two-step cluster analysis (TSC), which is a consistent method used for grouping the subjects and aggregate units based on the characteristics that they possess (29). In the cluster analysis, the idea is to explore the homogeneity in each cluster and the heterogeneity among the clusters to define a data structure. When the probability of the presence of a given characteristic in a cluster is above $50 \%$, this characteristic determines the cluster format (29). In this study, the main characteristic was the categorical variables of the regular consumption of each food group, that is, the presence or absence of food groups. The unit of analysis was the individual, and in the pre-agglomeration step, TSC checked each data; in this case, each senior pointing out whether the individual could be added to a previously formed cluster or a new cluster needed to be created for him/her (30).

The descriptive analysis includes the estimates of medians and interquartile ranges for the quantitative variables and the frequency distribution for the categorical variables. Multinomial logistic regression was used to identify the association between the independent variables of interest in this study and the dependent variable, the clusters of food consumption. Crude and adjusted odds ratios (OR) were estimated as well as their 95\% confidence intervals (CI). In this study, the independent variables that were associated with the dependent variable with $p<0.20$ in the univariate stage were included in the multiple multinomial logistic regression model according to Hosmer and Lemeshow (31). Data analysis was performed using the IBM SPSS software, version 20.0. The level of significance for rejecting the null hypothesis was $\alpha=0.05$. 
TABLE 2 | Socioeconomic characteristics, health and use of health services, lifestyle, and anthropometric indicators in the older adult sample, Viçosa, State of Minas Gerais, Brazil, 2009 ( $n=621)$.

\begin{tabular}{|c|c|c|c|c|}
\hline Variable & $n$ & $\%$ & Median & $\begin{array}{l}\text { Interquartile } \\
\text { range }\end{array}$ \\
\hline Sex female & 331 & 53.3 & & \\
\hline \multicolumn{5}{|l|}{ Age range } \\
\hline $60-69$ & 311 & 50.1 & & \\
\hline $70-79$ & 216 & 34.8 & & \\
\hline$\geq 80$ & 94 & 15.1 & & \\
\hline \multicolumn{5}{|l|}{ Education level } \\
\hline Never studied & 95 & 15.3 & & \\
\hline Less than eight years of study & 397 & 63.9 & & \\
\hline Eight years of study or more & 129 & 20.8 & & \\
\hline \multicolumn{5}{|l|}{ Individual income/month (quartiles) } \\
\hline Q1 (US\$ 0-210.99) & 72 & 11.6 & & \\
\hline Q2 (US\$ 211.00-273.49) & 234 & 37.7 & & \\
\hline Q3 (US\$ 237.50-670.99) & 153 & 24.6 & & \\
\hline Q4 ( $\geq$ US\$ 671.00) & 153 & 24.6 & & \\
\hline Lived alone & 66 & 10.6 & & \\
\hline \multicolumn{5}{|l|}{ Self-perception of healtha } \\
\hline Very good/good & 272 & 43.8 & & \\
\hline Regular & 289 & 46.5 & & \\
\hline Poor/very poor & 38 & 6.1 & & \\
\hline \multicolumn{5}{|c|}{ Number of doctor's appointments (in the preceding year) ${ }^{a}$} \\
\hline None & 45 & 7.2 & & \\
\hline $1-5$ & 449 & 72.3 & & \\
\hline$\geq 6$ & 126 & 20.3 & & \\
\hline $\begin{array}{l}\text { History of at least one hospitalization } \\
\text { (in the preceding year) }\end{array}$ & 94 & 15.1 & & \\
\hline Functional disability & 100 & 16.1 & & \\
\hline Difficulty with eating & 53 & 8.5 & & \\
\hline Difficulty with food preparation & 66 & 10.6 & & \\
\hline $\begin{array}{l}\text { Polypharmacy (in the preceding } 15 \\
\text { days) }\end{array}$ & 224 & 36.1 & & \\
\hline History of diabetes & 139 & 22.4 & & \\
\hline History of dyslipidemia & 353 & 56.8 & & \\
\hline History of high blood pressure & 475 & 76.5 & & \\
\hline History of depression & 117 & 18.8 & & \\
\hline \multicolumn{5}{|l|}{ Consumption of alcoholic beverages ${ }^{a}$} \\
\hline Yes & 209 & 33.7 & & \\
\hline No, but used to drink formerly & 205 & 33.0 & & \\
\hline Never drank at all & 206 & 33.2 & & \\
\hline \multicolumn{5}{|l|}{ Smoking habit ${ }^{a}$} \\
\hline Yes & 67 & 10.8 & & \\
\hline No, but used to smoke formerly & 207 & 33.3 & & \\
\hline Never smoked at all & 345 & 55.6 & & \\
\hline $\begin{array}{l}\text { Decrease in the food intake (in the } \\
\text { preceding } 3 \text { months) }\end{array}$ & 78 & 12.6 & & \\
\hline \multicolumn{5}{|l|}{ Anthropometric variables ${ }^{b}$} \\
\hline $\mathrm{BMI}\left(\mathrm{kg} / \mathrm{m}^{2}\right)$ & & & 26.37 & $23.49-29.53$ \\
\hline WC (cm) & & & 95.30 & $87.60-103.10$ \\
\hline WHR & & & 0.96 & $0.91-1.00$ \\
\hline WHtR & & & 0.60 & $0.55-0.65$ \\
\hline
\end{tabular}

BMI, body mass index; WC, waist circumference; WHR, waist-to-hip ratio; WHtR, waist-to-height ratio.

${ }^{a}$ Not informed by a part of the sample.

${ }^{b}$ Not measured/calculated in a part of the sample.
TABLE 3 | Frequency of regular consumption of food groups, listed under healthy and unhealthy eating indicators, Viçosa, State of Minas Gerais, Brazil, 2009 $(n=621)$.

\begin{tabular}{lcc}
\hline Food groups & \multicolumn{2}{c}{ Consumption } \\
\cline { 2 - 3 } & $n$ & $\%$ \\
\hline Healthy eating indicators & 581 & \\
Beans & 443 & 93.6 \\
Vegetables & 440 & 71.3 \\
Green vegetables & 443 & 70.9 \\
Fruits & 170 & 71.3 \\
Skim milk and low-fat dairy products & & 27.4 \\
Unhealthy eating indicators & 553 & \\
Fatty/processed meat & 385 & 89.0 \\
Fat & 359 & 62.0 \\
Whole milk & 183 & 57.8 \\
Processed foods in general & 54 & 29.5 \\
Sweets & 13 & 8.7 \\
Soda & & 2.1 \\
\hline
\end{tabular}

\section{RESULTS}

Regarding the socioeconomic characteristics of the participants, the majority were female, between 60 and 69 years old, had $<8$ years of study, and resided with someone else (Table 2). Regarding income, most seniors fell under the second quartile (individual income between US\$211.00 and US\$237.49 per month). The lower limit corresponded to the minimum wage converted into American dollars according to the rates at the time of the study. Most of the seniors perceived their health to be regular and had a history of one to five doctor's appointments, with $15.1 \%$ reporting a history of hospitalization in the year preceding the survey. Functional ability was considered inadequate for about $16 \%$ of the individuals, and a minority reported difficulty with eating, difficulty with food preparation, and some decrease in food intake over the 3 months prior to the survey. Polypharmacy was identified in a third of the participants as well as the consumption of alcoholic beverages; however, the majority had never smoked. Regarding the diagnosis of non-communicable diseases, high blood pressure was the most prevalent, followed by a history of dyslipidemia, a history of diabetes, and depression. Anthropometric variables are presented as median and interquartile range (Table 2).

Most of the individuals used to consume foods that were listed under "healthy eating indicators," except for skim milk and low-fat dairy products. Of note is the regular consumption (five times or more per week) of beans by nearly the entire sample. In relation to "unhealthy eating indicators," we identified a low frequency of consumption of sweets and soda. On the other hand, the consumption of fatty/processed meat at least once a week was reported by the majority of the seniors (Table 3).

The analysis generated three clusters using the information regarding the individual's food consumption, which were named according to the behavior of the seniors that they included. The first was "unhealthy," the second "less unhealthy," and the 


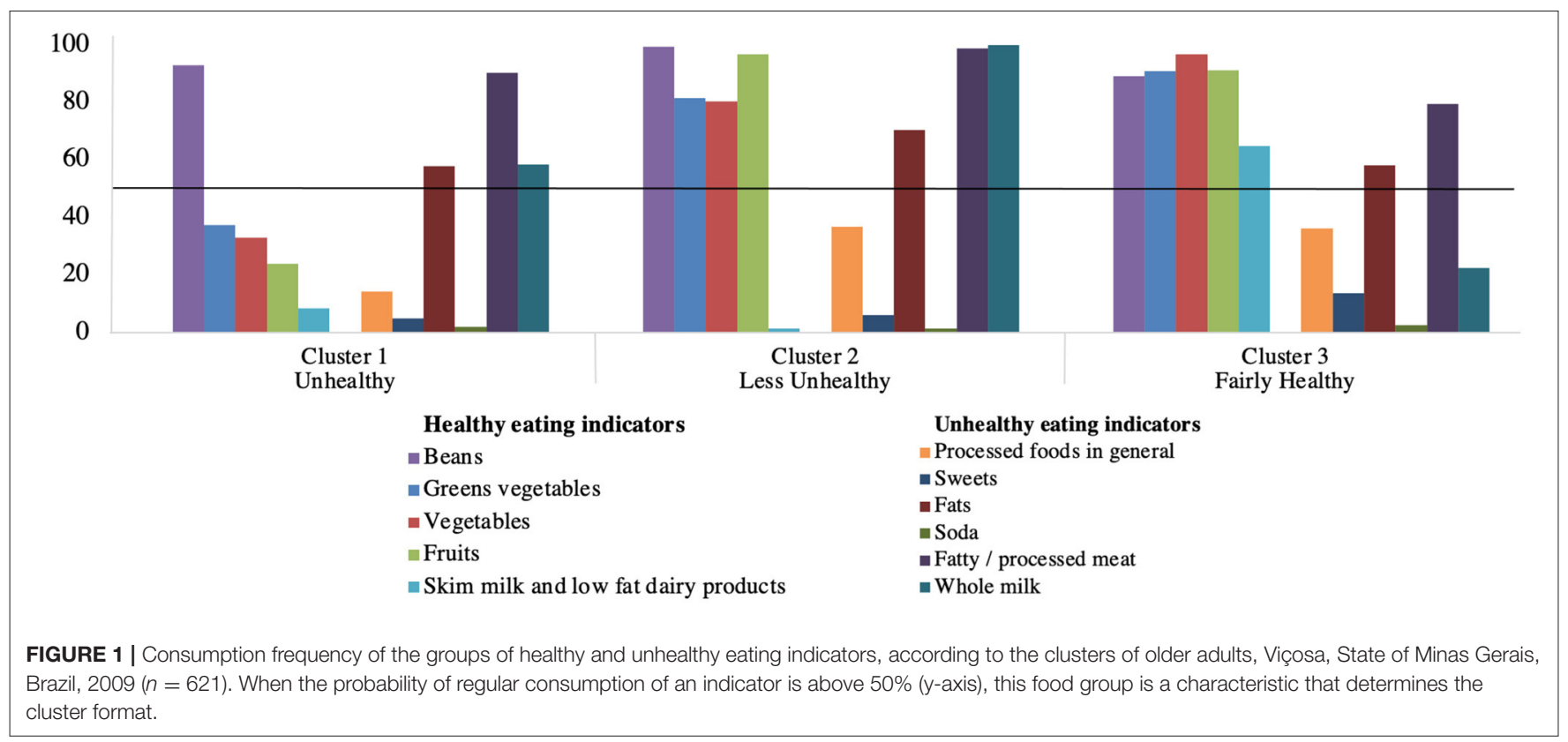

third "fairly healthy" (Figure 1). The cluster "unhealthy" (32.2\% of the sample) was characterized by older adults who regularly consumed beans, fats, fatty/processed meats, and whole milk. The cluster "less unhealthy" was formed by $30.6 \%$ of the participants who regularly consumed beans, green vegetables, vegetables, and fruits as well as consumed fats, fatty/processed meats, and whole milk. The cluster "fairly healthy" was represented by $37.2 \%$ of the individuals who regularly consumed beans, green vegetables, vegetables, fruits, fats, fatty/processed meats, skim milk, and low-fat dairy products. Among the healthy eating indicators, we highlight the consumption of beans, as in the three clusters almost all the participants consumed this food regularly (five or more times per week). Similar behavior was observed in relation to the consumption of fats and fatty/processed meats, characterizing them as unhealthy eating indicators that were present in all clusters. Some food groups had a low frequency of consumption in all clusters, such as processed foods in general, sweets, and soda. Processed foods in general had an even lower consumption frequency in cluster 1 , and the sweets were slightly more frequent in cluster 3 .

In the univariate analysis, the variables associated with the clusters "unhealthy" and "less unhealthy" were education level, individual income, number of doctor's appointments, history of diabetes, history of dislipidemia, polypharmacy, consumption of alcoolic beverages, smoking habbit, reduction in food ingestion, and waist circumference (data not shown). The OR and the respective confidence intervals $(95 \% \mathrm{CI})$ of the multiple analyses between the socioeconomic and health conditions and clusters of food consumption in this older adult population are presented in Table 4. Individuals who never studied or with $<8$ years of study and those who reported at least six doctor's appointment in the prior year were more likely to belong to the clusters "unhealthy" and "less unhealthy." The seniors in quartiles 1 and 2 of individual income, those who reported one to five doctor's appointment in the prior year, and the former smokers had a greater chance to belong to the cluster "unhealthy." There was a borderline association of the cluster "unhealthy" with a history of diabetes (OR 0.6; 95\% CI 0.3,1.0; $p=0.051$ ), and there was also a borderline association of the cluster "less unhealthy" with a history of dyslipidemia (OR 0.6; 95\% CI 0.4,1.0; $p=0.054$ ).

\section{DISCUSSION}

This is the first Brazilian population-based study that obtained and described three profiles of older adults from the two-step cluster analysis concerning food consumption. We identified the food groups and eating habits that contributed to characterize these profiles, and we estimated the association of social and demographic variables, health and use of health services, lifestyle, and anthropometric indicators with these profiles.

The first cluster was identified as "unhealthy." Despite being characterized by the regular consumption of beans, a healthy eating indicator, their other three food groups were unhealthy eating indicators (whole milk, fatty/processed meats, and fats). Moreover, most of the seniors in the cluster "unhealthy" were not used to consuming fruits and vegetables regularly. The second cluster was classified as "less unhealthy" because, although it was characterized by the presence of fruits, green vegetables, and beans, it also included whole milk, fatty/processed meats, and fats. The third cluster was classified as "fairly healthy" because it differed from cluster 2, as it included skim milk and low-fat dairy products, and from cluster 1 by the consumption of all healthy eating indicators. Thus, this cluster represents individuals with a healthier food profile, as compared to the other two clusters, but is not completely healthy because it was also characterized by the consumption of fats and fatty/processed meats.

Changes in food consumption caused by modernization are of concern in all population groups, as they are characterized by 
TABLE 4 | Final results of the multiple analysis of the association among the sociodemographic and health conditions and the food consumption clusters ${ }^{a}$, Viçosa, State of Minas Gerais, Brazil, 2009 ( $n=621)$.

\begin{tabular}{|c|c|c|}
\hline \multirow[t]{3}{*}{ Variable } & Cluster 1 & Cluster 2 \\
\hline & Unhealthy & Less unhealthy \\
\hline & OR (Cl 95\%) & OR (Cl 95\%) \\
\hline \multicolumn{3}{|l|}{ Education level } \\
\hline Eight years of study or more & 1.0 & 1.0 \\
\hline Less than 8 years of study & $3.8(1.9-7.5)$ & $2.8(1.6-4.9)$ \\
\hline Never studied & $10.7(4.2-27.7)$ & $5.4(2.2-13.2)$ \\
\hline \multicolumn{3}{|l|}{ Individual income/month (quartiles) } \\
\hline Q4 ( $\geq$ US\$ 671.00) & 1.0 & 1.0 \\
\hline Q3 (US\$ 237.50-670.99) & $1.5(0.8-3.1)$ & $1.1(0.6-2.0)$ \\
\hline Q2 (US\$ 211.00-273.49) & $2.3(1.2-4.6)$ & $1.1(0.6-2.0)$ \\
\hline Q1 (US\$ 0-210.99) & $2.4(1.1-5.5)$ & $1.1(0.5-2.3)$ \\
\hline \multicolumn{3}{|l|}{ Number of doctor's appointments } \\
\hline None & 1.0 & 1.0 \\
\hline $1-5$ & $0.3(0.1-0.8)$ & $0.6(0.2-1.6)$ \\
\hline$\geq 6$ & $0.3(0.1-0.9)$ & $0.3(0.1-0.9)$ \\
\hline \multicolumn{3}{|l|}{ History of diabetes } \\
\hline No & 1.0 & 1.0 \\
\hline Yes & $0.6(0.3-1.0)$ & $0.8(0.4-1.3)$ \\
\hline \multicolumn{3}{|l|}{ History of dyslipidemia } \\
\hline No & 1.0 & 1.0 \\
\hline Yes & $0.7(0.5-1.2)$ & $0.6(0.4-1.0)$ \\
\hline \multicolumn{3}{|l|}{ Polypharmacy } \\
\hline No & 1.0 & 1.0 \\
\hline Yes & $0.7(0.4-1.1)$ & $0.8(0.5-1.2)$ \\
\hline \multicolumn{3}{|c|}{ Consumption of alcoholic beverages } \\
\hline Never drank at all & 1.0 & 1.0 \\
\hline No, but used to drink formerly & $1.4(0.8-2.5)$ & $1.1(0.6-1.9)$ \\
\hline Yes & $0.8(0.4-1.5)$ & $0.9(0.5-1.6)$ \\
\hline \multicolumn{3}{|l|}{ Smoking habit } \\
\hline Never smoked at all & 1.0 & 1.0 \\
\hline No, but used to smoke formerly & $1.8(1.1-3.1)$ & $1.6(0.9-2.6)$ \\
\hline Yes & $2.0(0.9-4.2)$ & $0.9(0.4-1.9)$ \\
\hline \multicolumn{3}{|l|}{ Reduction in food ingestion } \\
\hline No & 1.0 & 1.0 \\
\hline Yes & $1.6(0.8-3.4)$ & $1.7(0.8-3.5)$ \\
\hline \multicolumn{3}{|l|}{ WC $($ median $=95.3 \mathrm{~cm})$} \\
\hline Lesser than the median & 1.0 & 1.0 \\
\hline Larger than or equal to the median & $0.9(0.9-1.0)$ & $1.0(0.9-1.0)$ \\
\hline
\end{tabular}

"For this analysis, the cluster "fairly healthy" was the reference category. C195\%, 95\% confidence interval; OR, odds ratio; WC, waist circumference. Values in bold indicate factors independently associated with the "unhealthy" and "less unhealthy" clusters.

the replacement of fresh foods rich in nutrients with processed foods rich in sugar, fat, and additives (32). When it turns to older adults, monotonous food choices with low nutritional quality are the greatest risk $(33,34)$. Nevertheless, in this study, we observed a mix of high consumption of healthy eating indicators, such as fruits and vegetables, and unhealthy eating indicators, such as whole milk, fatty/processed meats, and fats. The consumption of processed foods, sweets, and soda did not characterize any cluster, which shows that the older adults in this sample still remained on a traditional diet despite that the cluster "unhealthy" had shown little variety.

Lower education level was found to be directly associated with the clusters "unhealthy" and "less unhealthy." Low education level is often a factor that negatively impacts the eating habits and leads to a greater risk of malnutrition as reported by previous epidemiological studies $(3,16,17,32,35,36)$. Giuli et al. (3), in an Italian study, identified that seniors with a higher education level consumed more beans, cereals, fruits, fish, red meat, and dairy products. In Brazil, another study observed a lower education level among aged individuals whose families revealed food insecurity (35), and Gadenz and Benvegnú (13) identified a positive association between more years of study and the consumption of fruits and vegetables by aged individuals. In the present study, the cluster "unhealthy" is an example of worse nutrition associated with low education. With more years of study, there may be greater access to information about the quality of food and the contribution of each food group to health. In addition, more often, higher education is also related to higher income, which will be discussed later. The only difference between the clusters "fairly healthy" and "less unhealthy" was the regular consumption of skim milk and low-fat dairy products in the first category and the consumption of whole milk in the second. Considering this, the results of the current study suggest that a higher education level (8 years of study or more) promotes access to information on healthy eating, making it reasonable to assume that it influences the habit of replacing whole milk with skim products when necessary. A review from Netherlands about dietary guidances confirms that dairy products are part of these food-based dietary guidelines because of their nutrient richness and emphasizes that low-fat or skimmed versions must be generally advocated (37). This result may also indicate that nutrition will be better with the tendency of increase in the education of older adults, a hypothesis that requires further investigation in the future. For now, this result evidences the need to promote nutrition education suitable for the low-educated older adult population with appropriate communication.

Lower income was also found to be directly associated with the cluster "unhealthy," that is, the seniors included in this cluster were more likely to possess an individual income less than US\$ 237.50 per month, marginally higher than the minimum wage of the time, when compared with the cluster "fairly healthy." Assumpção and colleagues also reported results in which seniors earning higher incomes revealed higher healthy eating scores (15). Total household income was significantly and positively associated with fruits and vegetables intake among older adults in the Canadian study of Riediger and Moghadasian (32). Despite the great offer and diversity of fruits and vegetables in Brazil, even at lower costs, it is still expected that the aged individuals with higher personal incomes enjoy greater purchasing power, which may encourage food choices with more quality and variety. The association observed between the lower socioeconomic level and low quality of diet suggests unequal access to food among the older adults, which is supported by the evidence that the 
cluster "unhealthy" was characterized by people with a more monotonous food consumption, lacking the important variety and quality provided by fruits, vegetables, skim milk, and lowfat dairy products. In this sense, policies must be developed to reduce income inequality and guarantee access to adequate food for older adult populations.

The variable "number of doctor's appointments" was inversely associated with the clusters "unhealthy" and "less unhealthy." The individuals assigned to the cluster "fairly healthy" had a higher number of consultations in the year preceding the survey. Gadenz and Benvegnú identified a similar behavior with aged individuals, revealing the direct association between adequate diet and a history of consultation with a nutritionist (13). An inference that can be drawn is that, because these seniors had sought more healthcare, they enjoyed greater access to information related to wise eating choices and therefore consumed more food considered as healthy eating indicators, such as fruits, vegetables, skim milk, and low-fat dairy products.

From the univariate analysis, the history of diabetes was inversely associated with the cluster "unhealthy," and the history of dyslipidemia was inversely associated with both clusters "unhealthy" and "less unhealthy." Both did not remain in the final model, but they were in the significance threshold $(p=0.051$ for diabetes and $p=0.054$ for dyslipidemia). It is possible that these morbidities resulted in greater demand/utilization of health services by the seniors and, consequently, provided greater access to information, culminating in better eating habits. This possible behavioral change, called reverse causality, was also reported by Assumpção and colleagues, who observed a better quality of diet among older adults with a reported diagnosis of diabetes (15). Thus, it is possible that the best diet quality can be due to the diagnosis of non-communicable chronic diseases, which demands the adoption of a healthy diet for accurate treatment.

Another condition directly associated with the cluster "unhealthy" was having been a former smoker. The individuals in this profile were more likely to have smoked and stopped this habit at some point in their lives. Due to the lack of information regarding the time of smoking exposure and the time that had lapsed between the interview and smoking cessation, this data can be extremely variable, and the relationship between this old habit and the present diet is not precise. Smoking is known to change the palatability of some foods, such as fruits, vegetables, dairy products, and even water (38), and the cessation of this habit can reawaken the ability to experience the taste of these foods $(38,39)$. Besides that, the adoption of a healthier behavior, such as smoking cessation, should be accompanied by an improvement in other aspects, like eating habits. Perhaps these changes are motivated by different reasons, which explains the results observed. The association between the current smoking habit and the cluster "unhealthy" in multiple analysis showed a trend toward significance $(p=0.066)$. Studies show the association between smoking and poor eating habits $(15,38,40,41)$. It is possible that the small number of smokers in this study ( $n=67 ; 10.8 \%$ ) has restricted the ability to identify this association in the sample under study.

It is worth emphasizing that all methods of evaluation of food intake have limitations, such as the possibility of memory bias, especially in aged individuals. The FFQ is considered an efficient tool for identifying the usual food consumption, speccially when conducted by trained interviewers, besides having a low cost and simple application (42). In addition, we believe that the monotony of the diet of the Brazilian older adults $(33,34)$ minimizes the limitations of the FFQ and the possible distortions in the results of the food profile of this population. The qualitative characteristic of the instrument used has not enabled the evaluation of the food portions consumed by the seniors. This fact impairs the comparison with some recommendations and a deeper evaluation of the diet.

A limitation inherent in the cross-sectional design is the inability to establish the temporal relationship of some of the associations observed. Nevertheless, they are consistent with the literature and generate hypotheses that need to be explored in longitudinal studies in order to recognize the determinants of the eating habits of older adults, and despite the limitations, they are important as a nutritional advice for these invididuals.

A possible limitation of the study is the fact that the health conditions and drug utilization information are self-reported. However, the way to obtain this information was based on instruments adopted by large national surveys that have already reported its satisfactory validity.

In conclusion, we identified three clusters called "unhealthy," "less unhealthy," and "fairly healthy" based on data from the food consumption of older adults in Brazil. Although all clusters have been characterized by the consumption of some unhealthy foods, the subjects presented traditional eating habits in this study, especially showing a low consumption of soda, sweets, and processed foods in general and a high consumption of beans. However, the cluster "unhealthy" was composed of individuals without the habit of regular consumption of fruits and vegetables. We observed an association between low education level, low income, few doctor's appointments, and the fact of being a former smoker with poor diet quality. The evidence indicates the profile of seniors who require greater attention and care related to improved nutrition. Nutrition education public policies and health actions must be focused on and appropriate for the illiterate or semi-literate aged individuals with lower income and those who do not seek guidance. In light of the obtained results, efforts should be made to encourage older adults to keep the traditional and healthy eating habits, with greater access to consumption of fruits, vegetables, and beans and low consumption of soda, sweets, and processed foods.

\section{DATA AVAILABILITY STATEMENT}

The raw data supporting the conclusions of this article will be made available by the authors, without undue reservation.

\section{ETHICS STATEMENT}

This study was reviewed and approved by Research Ethics Committee of the Federal University of Viçosa (ref. 27/2008). 
The participants provided their written informed consent to participate in this study.

\section{AUTHOR CONTRIBUTIONS}

LL, MP, and AR contributed to the conception and design of the study. AR contributed to the acquisition of data. LL and AR wrote the first draft with contributions from MP, LA, and CM. All the authors reviewed and commented on the subsequent drafts of the manuscript.

\section{REFERENCES}

1. de Lima TJV, Arcieri RM, Garbin CAS, Moimaz SAS. Humanização na atenção à saúde do idoso. Saude e Soc. (2010) 19:866-877. doi: 10.1590/S0104-12902010000400013

2. Lopes ACS, Caiaffa WT, Sichieri R, Mingoti SA, Lima-Costa MF. Consumo de nutrientes em adultos e idosos em estudo de base populacional: projeto Bambuí. Cad Saude Publica. (2005) 21:1201-9. doi: 10.1590/S0102-311X2005000400022

3. Giuli C, Papa R, Mocchegiani E, Marcellini F. Dietary habits and ageing in a sample of Italian older people. J Nutr Health Aging. (2012) 16:875-9. doi: 10.1007/s12603-012-0080-6

4. Inzitari M, Doets E, Bartali B, Benetou V, Di Bari M, Visser M, et al. Nutrition in the age-related disablement process. J Nutr Heal Aging. (2011) 15:599-604. doi: 10.1007/s12603-011-0053-1

5. Banerjee S. Multimorbidity-older adults need health care that can count past one. Lancet. (2015) 385:587-9. doi: 10.1016/S0140-6736(14)61596-8

6. Zhu J, Xiang Y-B, Cai H, Li H, Gao Y-T, Zheng W, et al. A prospective investigation of dietary intake and functional impairments among the elderly. Am J Epidemiol. (2018) 187:2372-86. doi: 10.1093/aje/kwy156

7. Ashby-Mitchell K, Peeters A, Anstey K. Role of dietary pattern analysis in determining cognitive status in elderly Australian adults. Nutrients. (2015) 7:1052-67. doi: 10.3390/nu7021052

8. Bajerska J, Wozniewicz M, Suwalska A, Jeszka J. Eating patterns are associated with cognitive function in the elderly at risk of metabolic syndrome from rural areas. Eur Rev Med Pharmacol Sci. (2014) 18:3234-3245.

9. Hernández-Galiot A, Goñi I. Adherence to the Mediterranean diet pattern, cognitive status and depressive symptoms in an elderly non-institutionalized population. Nutr Hosp. (2017) 34:338-44. doi: 10.20960/nh.360

10. Candía S, Candia P, Mena RP, Durán Agüero S. Calidad de la alimentación de adultos mayores de Santiago de Chile. Rev Esp Geriatr Gerontol. (2019) 54:147-50. doi: 10.1016/j.regg.2019.01.002

11. Guligowska AR, Pigłowska M, migielski J, Kostka T. Inappropriate pattern of nutrient consumption and coexistent cardiometabolic disorders in elderly people from Poland. Pol Arch Med Wewn. (2015) 125:521-31. doi: 10.20452/pamw.2959

12. Fernandes DP de S, Duarte MSL, Pessoa MC, Franceschini S do CC, Ribeiro AQ. Evaluation of diet quality of the elderly and associated factors. Arch Gerontol Geriatr. (2017) 72:174-80. doi: 10.1016/j.archger.2017.05.006

13. Gadenz SD, Benvegnú LA. Hábitos alimentares na prevenção de doenças cardiovasculares e fatores associados em idosos hipertensos. Cien Saude Colet. (2013) 18:3523-33. doi: 10.1590/S1413-81232013001200009

14. Pereira IF da S, Vale D, Bezerra MS, Lima KC de, Roncalli AG, Lyra C de O. Padrões alimentares de idosos no Brasil: Pesquisa Nacional de Saúde, 2013. Cien Saude Colet. (2020) 25:1091-102. doi: 10.1590/1413-81232020253.01202018

15. Assumpção D, Domene SMÁ, Fisberg RM, Barros MBA. Qualidade da dieta e fatores associados entre idosos: estudo de base populacional em Campinas, São Paulo, Brasil. Cad Saude Publica. (2014) 30:1680-94. doi: 10.1590/0102-311X00009113

16. Viebig RF, Pastor-Valero M, Scazufca M, Menezes PR. Consumo de frutas e hortaliças por idosos de baixa renda na cidade de São Paulo. Rev Saude Publica. (2009) 43:806-13. doi: 10.1590/S0034-89102009005000048

\section{FUNDING}

This work was supported by the National Council of Research and Development - CNPq under grants numbers 579255/20085 and 474689-2008-5; and Coordination of Improvement of Higher Education Personnel - CAPES under grant number 23038.039412/2008-73. CNPq and CAPES had no role in study design, in the collection, analysis and interpretation of data, in the writing of the report and in the decision to submit the article for publication.

17. Gomes AP, Soares ALG, Gonçalves H. Baixa qualidade da dieta de idosos: estudo de base populacional no sul do Brasil. Cien Saude Colet. (2016) 21:3417-28. doi: 10.1590/1413-812320152111.175 02015

18. Gonçalves IB, Lebrão ML, de Oliveira Duarte YA, Wagner GA, Zanetta DMT. Nutrition status of elderly smokers and former smokers of São Paulo City, Brazil. Rev Bras Epidemiol. (2018) 21(Suppl. 2):e180013. doi: 10.1590/1980-549720180013.supl.2

19. Nascimento CDM, Ribeiro AQ, Cotta RMM, Acurcio FDA, Peixoto SV, Priore SE, Franceschini SDCC. Factors associated with functional ability in Brazilian elderly. Arch Gerontol Geriatr. (2012) 54:e89-94. doi: 10.1016/j.archger.2011.08.005

20. Fiedler MM, Peres KG. Capacidade funcional e fatores associados em idosos do Sul do Brasil: um estudo de base populacional. Cad Saude Publica. (2008) 24:409-15. doi: 10.1590/S0102-311X2008000200020

21. Silva R, Schmidt O, Silva S. Polifarmácia em geriatria. Rev Assoc Med Rio Grande Do Sul. (2012) 56:164-74.

22. Gomes VP, Silva MT, Galvão TF. Prevalence of medicine use among Brazilian adults: a systematic review. Cienc e Saude Coletiva. (2017) 22:2615-26. doi: 10.1590/1413-81232017228.29412016

23. Lima-Costa MF, Matos DL, Camargos VP, Macinko J. Tendências em dez anos das condições de saúde de idosos brasileiros: evidências da pesquisa nacional por amostra de domicílios $(1998,2003,2008)$. Cienc e Saude Coletiva. (2011) 16:3689-96. doi: 10.1590/S1413-81232011001000006

24. Lima-Costa MF, De Andrade FB, Souza PRB De, Neri AL, Duarte YADO, Castro-Costa E, et al. The Brazilian Longitudinal Study of Aging (ELSI-Brazil): objectives and design. Am J Epidemiol. (2018) 187:1345-53. doi: 10.1093/aje/kwx387

25. Nascimento C de M, Oliveira C de, Firmo JOA, Lima-Costa MF, Peixoto SV. Prognostic value of disability on mortality: 15-year follow-up of the Bambuí cohort study of aging. Arch Gerontol Geriatr. (2018) 74:112-7. doi: 10.1016/j.archger.2017.10.011

26. Vellas B, Guigoz Y, Garry PJ, Nourhashemi F, Bennahum D, Lauque S, Albarede J-L. The Mini Nutritional Assessment (MNA) for grading the nutritional state of elderly patients: presentation of the MNA, history and validation. Nutrition. (1999) 15:116-22. doi: 10.1016/S0899-9007(98) 00171-3

27. World Health Organization (WHO). Obesity Preventing and Managing the Global Epidemic. Geneva: WHO Consultation on Obesity (1998).

28. Ministério da Saúde do Brasil. Vigitel Brasil 2016. Saúde Suplementar: Vigilância de Fatores de Risco e Proteção Para doenças Crônicas por Inquérito Telefônico. Brasília: Ministério da Saúde (2017).

29. Mingoti SA. Análise de Dados Através de Métodos de Estatística Multivariada: Uma Abordagem Aplicada. Belo Horizonte: Editora UFMG (2013).

30. IBM Corporation. TwoStep Cluster Analysis. IBM Doc. (2000). Available online at: https://www.ibm.com/docs/en/spss-statistics/27.0.0?topic= features-twostep-cluster-analysis (accessed April 22, 2021).

31. Hosmer DW, Lemeshow S. Applied Logistic Regression. 3rd ed. Hoboken, NJ: Wiley (2013).

32. Riediger ND, Moghadasian MH. Patterns of fruit and vegetable consumption and the influence of sex, age and socio-demographic factors among Canadian elderly. J Am Coll Nutr. (2008). 27:306-13. doi: 10.1080/07315724.2008.10719704 
33. Freitas AMDP, Philippi ST, Ribeiro SML. Listas de alimentos relacionadas ao consumo alimentar de um grupo de idosos: análises e perspectivas. Rev Bras Epidemiol. (2011) 14:161-77.

34. Carlos JV, Rolin S, Bueno MB, Fisberg RM. Porcionamento dos principais alimentos e preparações consumidos por adultos e idosos residentes no município de São Paulo, Brasil. Rev Nutr. (2008) 21:383-91. doi: 10.1590/S1415-52732008000400002

35. Marín-León L, Segal-Corrêa AM, Panigassi G, Maranha LK, Sampaio M de FA, Pérez-Escamilla R. A percepção de insegurança alimentar em famílias com idosos em Campinas, São Paulo, Brasil. Cad Saude Publica. (2005) 21:1433-40. doi: 10.1590/S0102-311X2005000500016

36. Kalan U, Arik F, Isik AT, Soysal P. Nutritional profiles of older adults according the Mini-Nutritional Assessment. Aging Clin Exp Res. (2020) 32:673-80. doi: 10.1007/s40520-019-01235-1

37. van Staveren WA, de Groot LPGM. Evidence-based dietary guidance and the role of dairy products for appropriate nutrition in the elderly. J Am Coll Nutr. (2011) 30:429S-37. doi: 10.1080/07315724.2011.10719987

38. McClernon FJ, Westman EC, Rose JE, Lutz AM. The effects of foods, beverages, and other factors on cigarette palatability. Nicotine Tob Res. (2007) 9:505-10. doi: 10.1080/14622200701243177

39. Tamborindeguy CC, Moraes CB. Mudanças de peso e comportamento alimentar em ex-tabagistas. Discip Sci. (2009) 10:107-14.
40. Lv J, Liu Q, Ren Y, Gong T, Wang S, Li L. Socio-demographic association of multiple modifiable lifestyle risk factors and their clustering in a representative urban population of adults: a cross-sectional study in Hangzhou, China. Int J Behav Nutr Phys Act. (2011) 8:40-52. doi: 10.1186/1479-58 68-8-40

41. Haibach JP, Homish GG, Giovino G a. A longitudinal evaluation of fruit and vegetable consumption and cigarette smoking. Nicotine Tob Res. (2013) 15:355-63. doi: 10.1093/ntr/nts130

42. Willett W. "Food Frequency Methods," in Nutritional Epidemiology. New York, NY: Oxford University Prees. p. 70-98.

Conflict of Interest: The authors declare that the research was conducted in the absence of any commercial or financial relationships that could be construed as a potential conflict of interest.

Copyright (C) 2021 Loureiro, Almeida, Machado, Pessoa, Duarte, Franceschini and Ribeiro. This is an open-access article distributed under the terms of the Creative Commons Attribution License (CC BY). The use, distribution or reproduction in other forums is permitted, provided the original author(s) and the copyright owner(s) are credited and that the original publication in this journal is cited, in accordance with accepted academic practice. No use, distribution or reproduction is permitted which does not comply with these terms. 